\title{
Dissimilar Metal Joining of Aluminum to Steel by MIG Arc Brazing Using Flux Cored Wire
}

\author{
Taichi MURAKAMI, Kazuhiro NAKATA, Hongjun TONG ${ }^{11}$ and Masao USHIO \\ Joining and Welding Research Institute, Osaka University, Ibaraki, Osaka 567-0047 Japan. \\ 1) Welding Research \& Mechanical Engineering Dept., DAIHEN Corporation, Settsu, Osaka 566-0021 Japan.
}

(Received on February 10, 2003; accepted in final form on April 14, 2003)

\begin{abstract}
Dissimilar metal joining of aluminum to steel, which is difficult due to the formation of the brittle intermetallic compound at the interface of the welded joint, by DC pulsed MIG arc brazing in a lap joint with the flux cored Al-Si filler wire has been investigated for the application of the weight saving of automobiles. The major compound formed at the interface between steel and weld metal was determined to be $\mathrm{Al}_{7.4} \mathrm{Fe}_{2} \mathrm{Si}$ as the Al-Fe-Si ternary compound. The composition control of weld metal can suppress the growth of the intermetallic compound layer less than the thickness of $2.5 \mu \mathrm{m}$. In this condition, the transverse tensile strength of the welded joint was about $80 \mathrm{MPa}, 70 \%$ of that of Al base metal due to the fracture at HAZ on the aluminum side. The mechanism of the suppressed growth of the intermetallic compound layer during MIG arc brazing has been discussed.
\end{abstract}

KEY WORDS: dissimilar metal joining; arc brazing; aluminum; steel; intermetallic compound.

\section{Introduction}

The joining of aluminum to steel is very important from the viewpoint of the weight saving of transport systems such as automobile. However, the direct fusion joining is difficult owing to forming the brittle intermetallic compound. ${ }^{1,2)}$ The direct solid state joining can be carried out by controlling the thickness of the intermetallic compound layer within a few micrometers at the joint interface. In fact, as solid state joining process, diffusion bonding, friction welding, and explosive welding ${ }^{2-6)}$ are applicable. However, a joint shape available to these processes is extremely restricted. On the other hand, the fusion welding has not been adopted due to the difficulty in controlling the composition of a fusion zone, because each metal can be easily melted by high welding heat input. This results in severe growth of the brittle intermetallic compound layer. However, Katayama et al. and Schubert et al. recently reported the direct fusion welding of aluminum to steel sheet using a focused laser beam by controlling both the amount of fusion metal and the joint groove shape to suppress the melting of steel sheet. ${ }^{7-9)}$ As another approach, Achar et al. reported that the thickness of the intermetallic compound layer decreased by the use of the aluminum alloy filler metal containing Si in TIG arc welding. ${ }^{10)}$

To prevent the dissolution of steel in the weld metal, arc brazing has a high potential, which can make a continuous joint by the deposition of the fused filler metal onto the groove without the melting of the base metal. In this process, however, the oxide scale on the groove surface has detrimental effect to the wettability of the molten metal. In a conventional furnace brazing of aluminum alloy, flux is frequently used for removing the oxide scale and protecting the molten metal from surrounding atmosphere during joining, and the flux cored wire or sheet based on Al-Si alloy are commonly used as a filler metal.

In this study, as a possible joining process for the direct joining of aluminum to steel, we have selected MIG arc brazing, which is the method to melt steel base metal as less as possible, using the flux cored Al-Si alloy wire as a consumable electrode. Process parametric study on the formation of the dissimilar metal joint and the measurement of joint tensile strength associated with the thickness of the intermetallic compound layer at the joint interface was carried out, and the growth mechanism of the intermetallic compound layer at the interface was discussed.

\section{Experimental}

Cold rolled plain carbon steel sheet (SPCC) and industrial pure aluminum sheet (A1050P-H24), whose size were $300 \times 100 \times 2 \mathrm{~mm}$, were used for the lap joint welding. An aluminum sheet was lapped over a steel sheet on a copper backing plate (thickness: $3 \mathrm{~mm}$ ) without the gap between top and bottom sheets as shown in Fig. 1. The surface of work piece was cleaned by acetone before arc brazing. The DC pulsed MIG arc brazing was carried out using the flux cored wire in $1.6 \mathrm{~mm}$ diameter and argon as shielding gas at a flow rate of $15 \mathrm{~L} / \mathrm{min}$. Power source for the DC pulsed MIG arc brazing was controlled by the pulse frequency modulation so that the mean voltage was kept constant. A filler wire, which was used as a consumable electrode for MIG arc brazing, was BA $4047 \mathrm{~W}$ consisting of $\mathrm{Al}-12.0 \% \mathrm{Si}$ alloy with flux whose components were $\mathrm{CsF}, \mathrm{AlF}_{3}, \mathrm{KF}$ and 


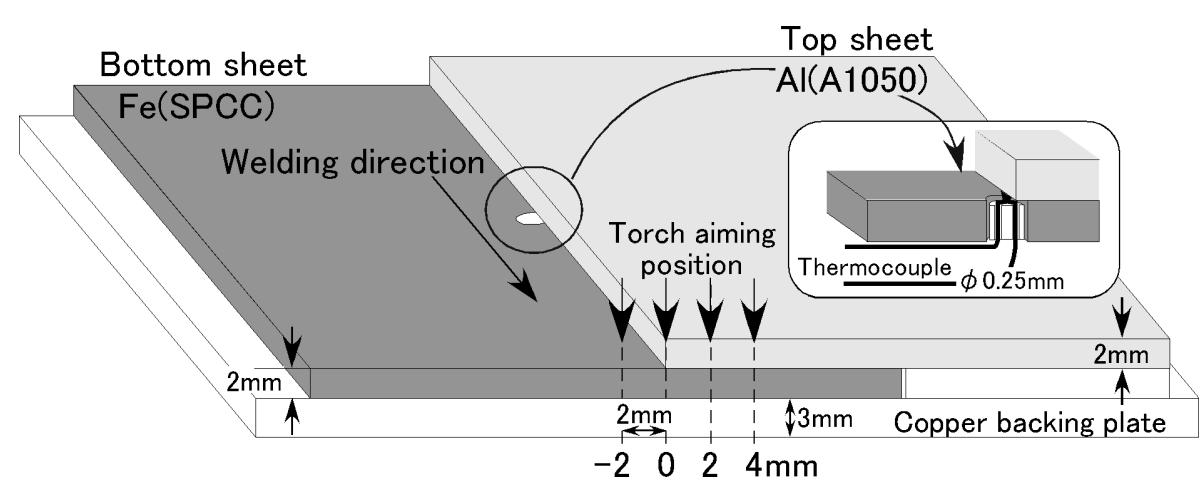

Fig. 1. Schematic diagram for setting a lap joint between aluminum top sheet and steel bottom sheet.

$\mathrm{Al}_{2} \mathrm{O}_{3}$. The wire feed rate was $4.0 \mathrm{~m} / \mathrm{min}$, and the mean welding current and voltage were controlled about $100 \mathrm{~A}$ and $17 \mathrm{~V}$, respectively. The welding speed was changed from 0.2 to $0.6 \mathrm{~m} / \mathrm{min}$. The aiming position of a MIG torch, which was the distance from the edge of the upper aluminum sheet as shown in Fig. 1, was changed from -2 to $+4 \mathrm{~mm}$. In some welding conditions, temperature change in weld metal, so called thermal cycle, was measured using $\mathrm{W}-5 \% \mathrm{Re} / \mathrm{W}-26 \% \mathrm{Re}$ thermocouple in $0.25 \mathrm{~mm}$ diameter as shown in Fig. 1.

Typical cross section of the work piece was observed using optical microscope. The composition of the intermetallic compound layer at the interface between steel and weld metal was determined using Electron Probe Micro Analyzer (EPMA) or Energy Dispersive X-ray Spectroscope (EDX) by ZAF correction. The composition of the weld metal was determined by Inductively Coupled Plasma Mass Spectrometry (ICP). In addition, the work piece was cut off in the width of $30 \mathrm{~mm}$, and transverse tensile test perpendicular to a welding direction was carried out to measure the joint tensile strength at the rate of $1 \mathrm{~mm} / \mathrm{min}$. The intermetallic compound layer at the fractured surface of the work piece at the interface between SPCC and weld metal was identified by X-ray diffraction (XRD).

\section{Results}

\subsection{Macro and Microstructures}

Bead appearance and typical cross section of the welded joint at the different welding speeds are shown in Fig. 2. The aiming position of torch is $0 \mathrm{~mm}$. The top and bottom sheets are aluminum and SPCC, respectively. The decrease in the welding speed resulted in the increase in the bead width and the decrease in the contact angle between SPCC and weld metal. These results are caused by the increase in the amount of the weld metal and the rise in the temperature of SPCC plate. At all welding speeds, the smooth bead was made, though many spatters were generated and the work piece was covered with the flux film, as observed typically at the low welding speed of $0.2 \mathrm{~m} / \mathrm{min}$ on the SPCC sheet.

Figure 3 shows the measured results of the thermal cycle of the weld bead at the fusion boundary on the bottom sheet (SPCC) during MIG arc brazing as shown in Fig. 1. The welding speed and the aiming position ranged from 0.2 to $0.6 \mathrm{~m} / \mathrm{min}$ and from -2 to $+4 \mathrm{~mm}$, respectively. Time " 0 " means the start of arc brazing. $T_{1}(973 \mathrm{~K})$ and $T_{2}(1128 \mathrm{~K})$

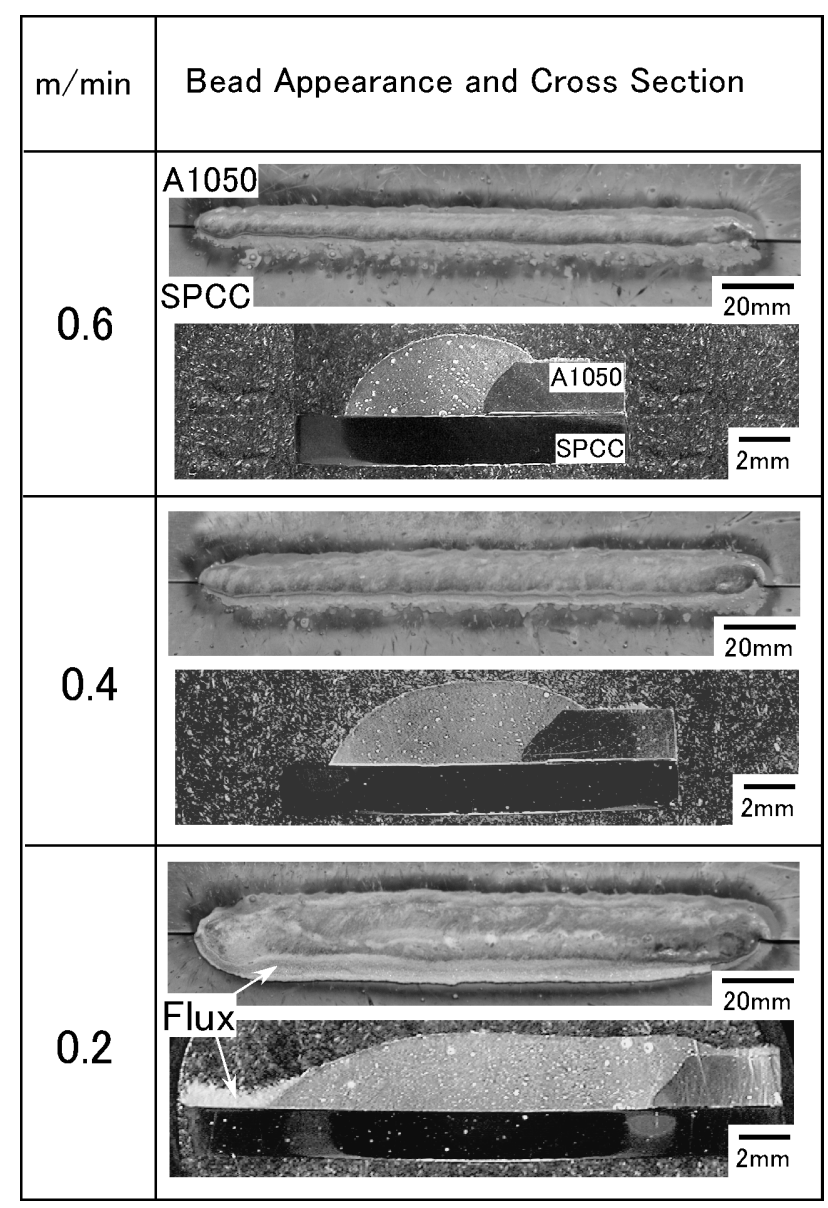

Fig. 2. Weld bead appearance and cross section of lap joint welded specimen at aiming position of $0 \mathrm{~mm}$ and welding speeds of $0.2,0.4$ and $0.6 \mathrm{~m} / \mathrm{min}$.

are the dissolution temperatures of $\mathrm{Al}_{7.4} \mathrm{Fe}_{2} \mathrm{Si}_{\text {and }} \mathrm{Al}_{9} \mathrm{Fe}_{2} \mathrm{Si}_{2}$, respectively. ${ }^{11)}$ The maximum temperature $\left(T_{\max }\right)$ increases with decreasing the welding speed. $T_{\max }$ exceeds $T_{1}$ at all the welding speed. At lower welding speed than $0.4 \mathrm{~m} / \mathrm{min}$, $T_{\max }$ exceeds even $T_{2}$. The cooling rate increases with increasing the welding speed. As to the effect of the aiming position on the thermal cycle measured at the welding speed of $0.2 \mathrm{~m} / \mathrm{min}, T_{\max }$ indicates the highest value at the aiming position of $0 \mathrm{~mm}$, meaning a weld central zone, and decreases with being apart from this position since the measurement point was moved apart from the weld central zone. However the cooling rate at the temperature less than $1000 \mathrm{~K}$ after the arc passes through the measurement position is almost the same at the different aiming positions. 


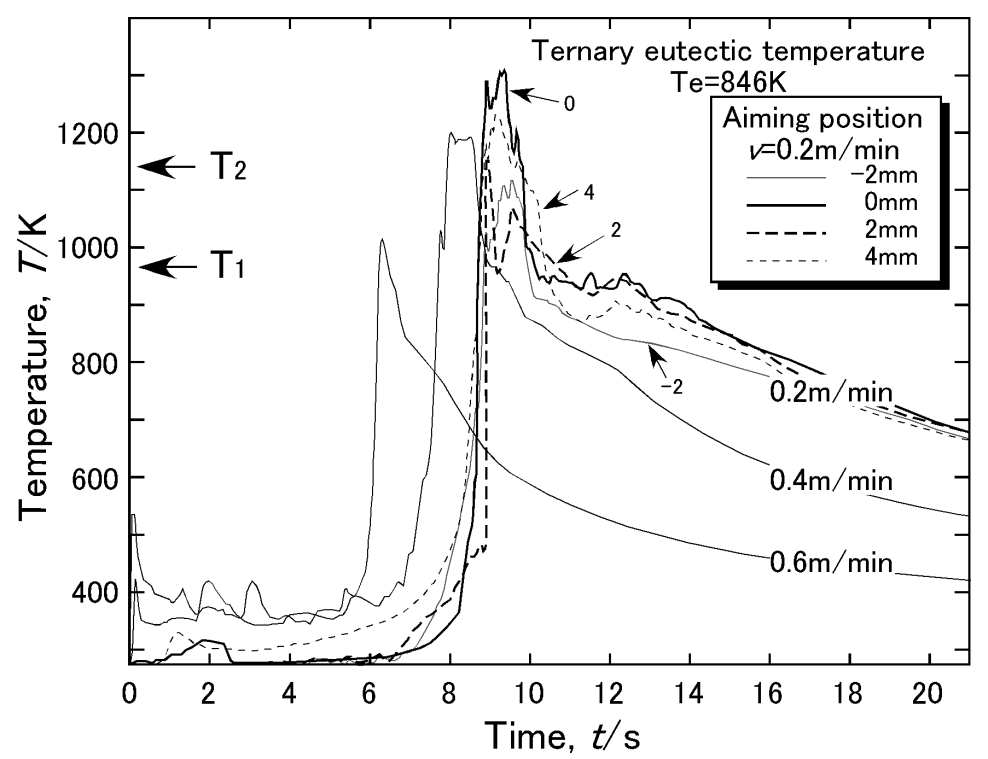

Fig. 3. Thermal cycles measured at fusion boundary adjacent to bottom sheet (SPCC) during MIG arc brazing.
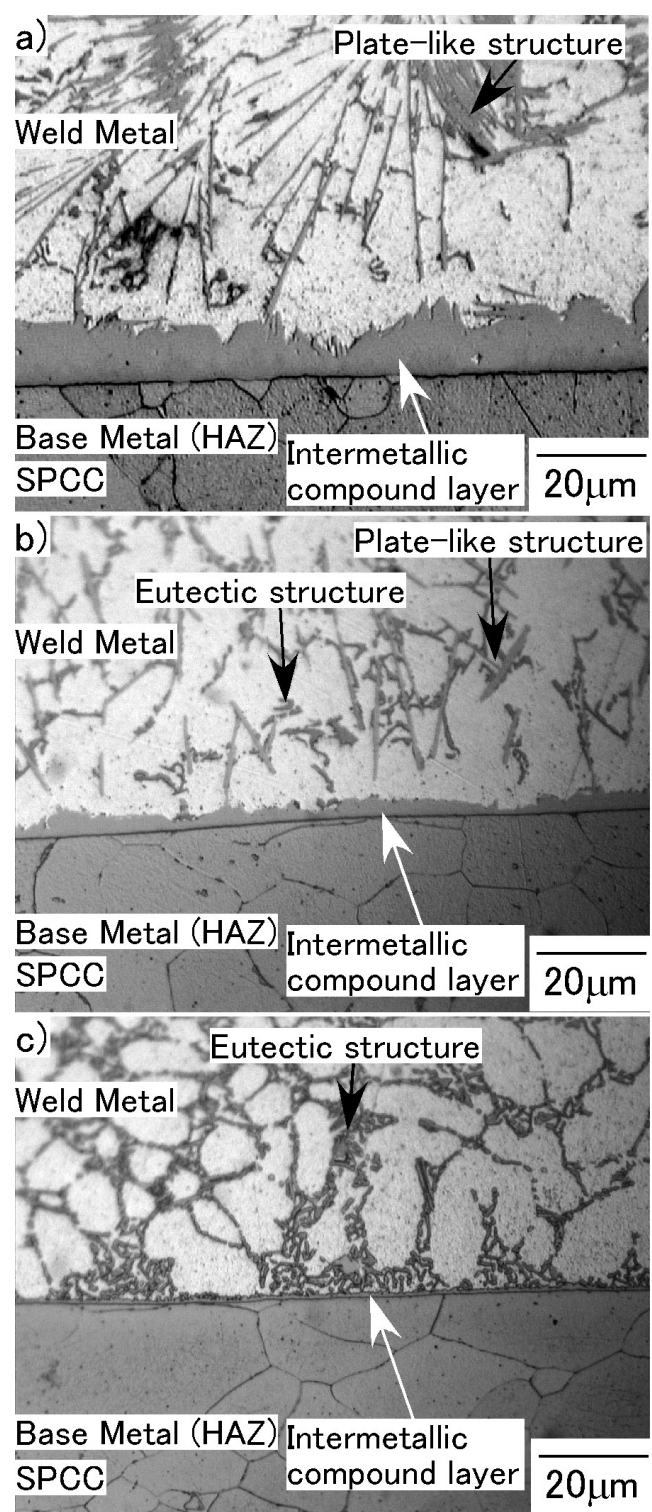

Fig. 4. Microstructures of interface between weld metal and base metal on SPCC at aiming position of $0 \mathrm{~mm}$ and welding speeds of (a) $0.2 \mathrm{~m} / \mathrm{min}$, (b) $0.4 \mathrm{~m} / \mathrm{min}$ and (c) $0.6 \mathrm{~m} / \mathrm{min}$.

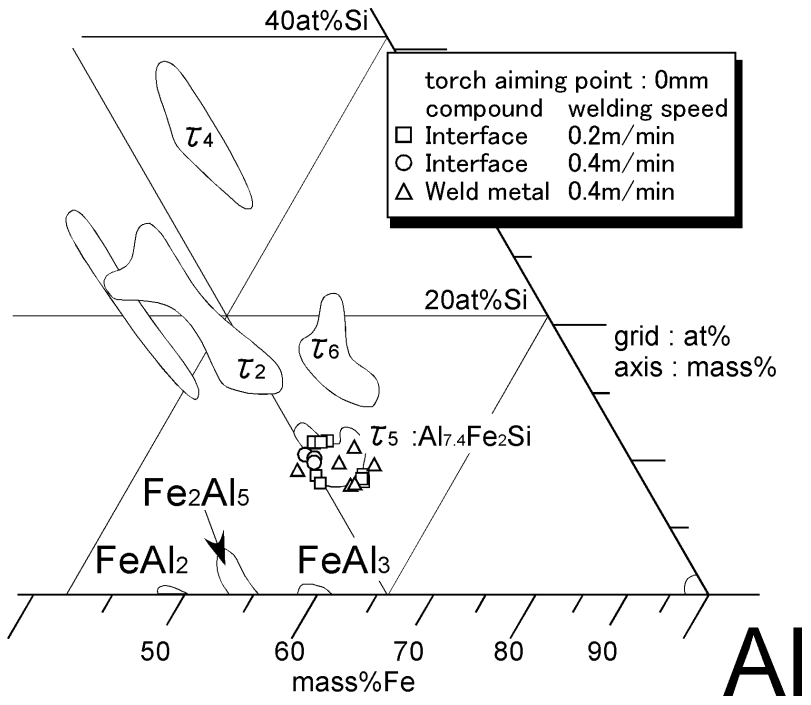

Fig. 5. Equilibrium $\mathrm{Al}-\mathrm{Fe}-\mathrm{Si}$ ternary phase diagram ${ }^{11)}$ in the aluminum corner showing distribution of equilibrium intermetallic compound phases, as reported by different authors, and the composition of intermetallic compound at the interface $(\square, \bigcirc)$ and in the weld metal $(\triangle)$.

Figure 4 shows microstructures of the interface between weld metal and base metal on SPCC at the welding speeds of $0.2,0.4$ and $0.6 \mathrm{~m} / \mathrm{min}$ and the aiming position of $0 \mathrm{~mm}$. In the weld metal, three different structures were observed; i.e., $\alpha$-aluminum as a matrix, $\mathrm{Al}-\mathrm{Si}$ eutectic as a network, and plate-like structure of $\mathrm{Al}-\mathrm{Fe}-\mathrm{Si}$ intermetallic compound. The compositions of the intermetallic compound at the interface and in the weld metal were plotted on the Al-Fe-Si ternary phase diagram as shown in Fig. 5. The ternary compound in the weld metal was determined to be $\mathrm{Al}_{7.4} \mathrm{Fe}_{2} \mathrm{Si}$. The amount of plate-like structure increases with decreasing the welding speed, and no plate-like structure was observed at the welding speed of $0.6 \mathrm{~m} / \mathrm{min}$ as shown in Fig. 4(c). On the other hand, the amount of eutectic structure increases with decreasing the welding speed. At the SPCC/weld metal interface, the intermetallic compound layer was formed, whose average thickness was 
much different, namely $11.1,2.5$ and $0.9 \mu \mathrm{m}$ at the welding speeds of $0.2,0.4$ and $0.6 \mathrm{~m} / \mathrm{min}$, respectively. The thickness of the intermetallic compound layers is plotted as a function of the welding speed at the different aiming positions as shown in Fig. 6. The thickness decreases with increasing the welding speed owing to the decrease of the heat input absorbed into the specimen. In addition, the thickness increases as the aiming position changed from plus to minus signs, namely moved from aluminum to SPCC side, which is remarkable at the welding speed of $0.2 \mathrm{~m} / \mathrm{min}$. Most of past reports ${ }^{1-3)}$ about the welding of aluminum alloy to steel using friction, spot and resistance weldings indicate that the formed compound layers at the joint interface are $\mathrm{Al}_{5} \mathrm{Fe}_{2}$ or $\mathrm{Al}_{3} \mathrm{Fe}$ as the binary compound. In this study, however, the formed compound layers at the interface at the welding speed of 0.2 and $0.4 \mathrm{~m} / \mathrm{min}$ were determined $\mathrm{Al}_{7.4} \mathrm{Fe}_{2} \mathrm{Si}$ as the $\mathrm{Al}-\mathrm{Fe}-\mathrm{Si}$ ternary compound, which was the same as the intermetallic compound formed in the weld metal, because the filler wire contained a high amount of $\mathrm{Si}, 12.0 \mathrm{mass} \%$. At the welding speed of $0.6 \mathrm{~m} / \mathrm{min}$, the formed intermetallic compound layer was difficult to be identified because the layer thickness was too thin. At the welding speed of $0.2 \mathrm{~m} / \mathrm{min}$ and the aiming position of $-2 \mathrm{~mm}$, other kind of intermetallic compound layer, which was determined $\mathrm{Al}_{3} \mathrm{Fe}$, was observed at the interface between SPCC and $\mathrm{Al}_{7.4} \mathrm{Fe}_{2} \mathrm{Si}$ layer.

The compositions of the weld metal including the intermetallic compound layer analyzed by ICP are plotted on the $\mathrm{Al}$ corner of the Al-Fe-Si ternary phase diagram with the thickness of the intermetallic compound layer as shown in Fig. 7. ${ }^{11)}$ These analyzed compositions correspond to those of fusion metal before the beginning of solidification. Iron content in the weld metal decreases with increasing the welding speed and with moving the aiming point to aluminum side. On this phase diagram, the composition of the fusion metal indicates that the compound crystallized as the primary phase is $\mathrm{Al}_{7.4} \mathrm{Fe}_{2} \mathrm{Si}$ at the welding speed of 0.2 and $0.4 \mathrm{~m} / \mathrm{min}$ at the aiming position of $0 \mathrm{~mm}$, shown by marks A and E in Fig. 7, respectively. This compound was identical with the formed intermetallic compound layer at the SPCC/weld metal interface. The more the content of iron increases, the more the formed compound layer thickens. It indicates that the thickness of the compound intimately depends on the composition of the weld metal.

\subsection{Tensile Properties}

Figure 8 shows the macrostructure on the cross section of the fractured welded joint after the transverse tensile test. Three different fracture modes were obtained; i.e. at HAZ in aluminum top sheet (Mode 1), the aluminum/weld metal interface (Mode 2) and the SPCC/weld metal interface (Mode 3). At fracture mode 1 and 3, many blow holes in the weld metal were occasionally observed, though those blow holes have no influence on the fracture mode. Figure 9 shows relation between the tensile or shear strengths of the welded joint and the thickness of the intermetallic compound layer together with the previous data reported on the welded joint of aluminum to stainless steel. ${ }^{12,13)}$ The shear strength at mode 3 is defined as the maximum load divided by the area of the fractured surface, which is the product of the joint width $(30 \mathrm{~mm})$ by the bead width. The shear

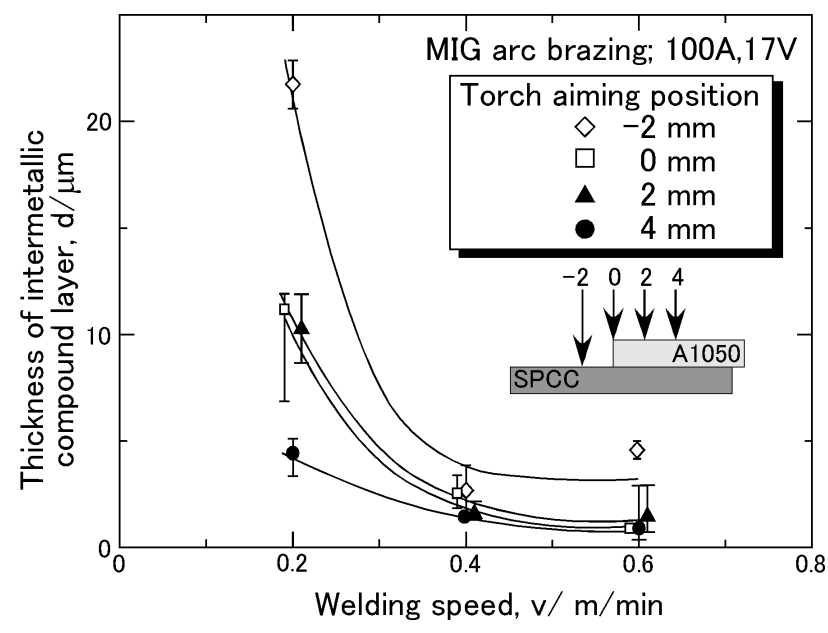

Fig. 6. Relation between thickness of formed intermetallic compound layer at SPCC/weld metal interface and welding speed at different torch aiming positions.

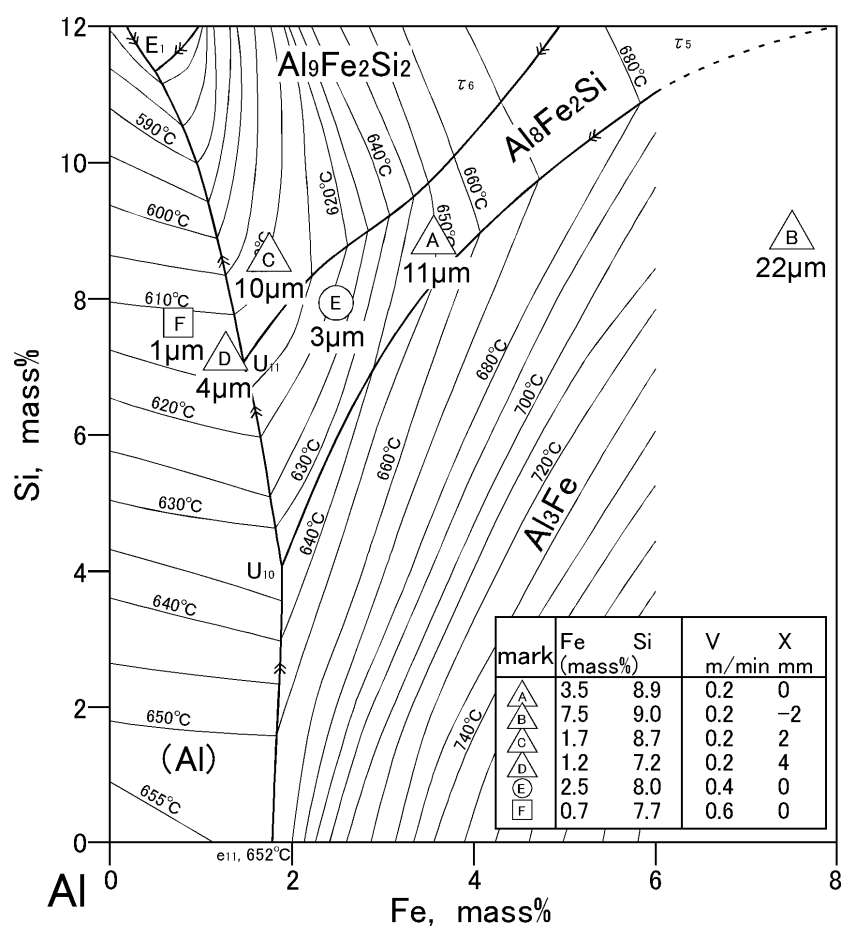

Fig. 7. Concentration of weld metal determined by ICP plotted on phase diagram at $\mathrm{Al}$ corner of $\mathrm{Al}-\mathrm{Fe}-\mathrm{Si}$ system together with the thickness of the intermetallic compound layer.

strength decreases with increasing the thickness of intermetallic compound layer. The welded joint with an undercut along the fusion boundary at the aluminum/weld metal interface fractured at mode 2 , because the minimum thickness of a tensile test specimen appeared at the undercut zone, at which stress concentration occurred during tensile test. The highest tensile strength of the welded joint was obtained at thinner than approximately $2.5 \mu \mathrm{m}$. In this case, the welded joint was fractured at HAZ in aluminum side with Mode 1 , and the tensile strength indicated from 75 to $80 \mathrm{MPa}$, equaled almost to $70 \%$ of that of aluminum base metal, $110 \mathrm{MPa}$ due to the softening in HAZ by the heat affection.

Kawakatsu et al. has reported the dissimilar metal braz- 
a) Mode 1

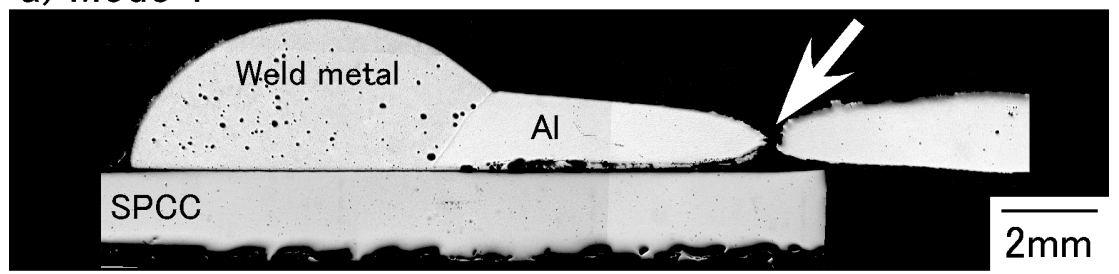

b) Mode 2

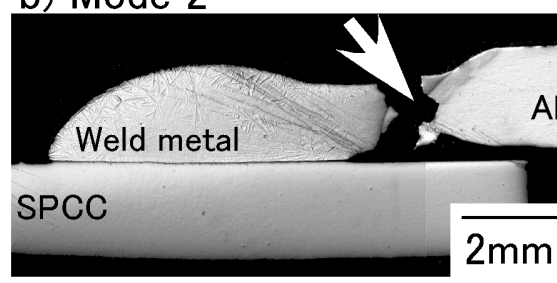

c) Mode 3

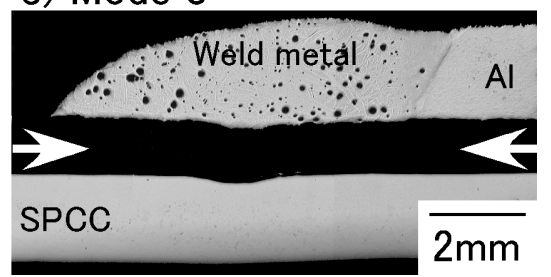

Fig. 8. Macrostructure of fractured joint, (a) Mode 1; fractured at HAZ in aluminum base metal, (b) Mode 2; fractured at aluminum/weld metal interface and (c) Mode 3; fractured at SPCC/weld metal interface. White arrows show the fractured position.

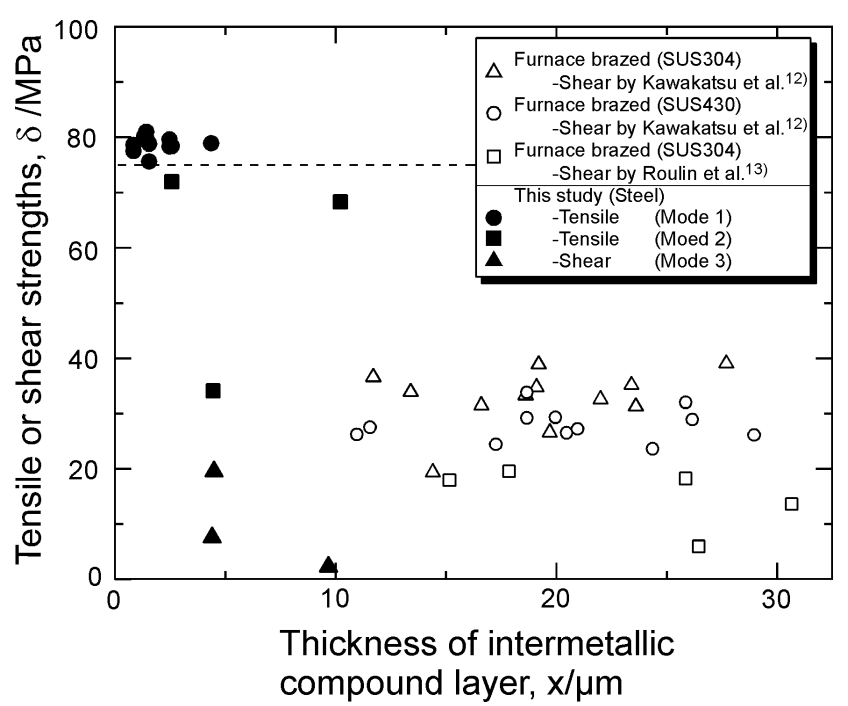

Fig. 9. Relation between tensile and shear strengths of welded joint and thickness of formed intermetallic compound layer at SPCC/weld metal interface in comparison with furnace brazed aluminum/SUS304 and SUS430 joints.

ing of pure aluminum (A1100) to stainless steel (SUS 304 and 430) using $\mathrm{Al}-7.5 \% \mathrm{Si}$ solder and the flux of the $\mathrm{LiCl}-$ $\mathrm{KCl}-\mathrm{NaF}-\mathrm{ZnCl}_{2}$ system by the furnace brazing at $893 \mathrm{~K}^{12)}$ Roulin et al. has reported the dissimilar metal brazing of pure aluminum (A1100) to stainless steel (SUS304) using $\mathrm{Al}-12 \% \mathrm{Si}$ solder by the furnace brazing at $873 \mathrm{~K} .{ }^{13)}$ They reported that all joints, of which the intermetallic compound layer grew above $10 \mu \mathrm{m}$, fractured at the stainless steel/fused solder metal interface in tensile test. Their tensile strength data of all joints were below $40 \mathrm{MPa}$. In contrast, MIG arc brazing can suppress the thickness of the intermetallic compound layer to be much thinner than that by the furnace brazing. Therefore, stronger joint with HAZ fracture of aluminum side, can be obtained by MIG arc brazing.

The X-ray diffraction profiles of the fractured surface of the welded joint fractured at the SPCC/weld metal interface (mode 3) are shown in Fig. 10. The welding speed and the aiming position of this welded joint were $0.2 \mathrm{~m} / \mathrm{min}$ and

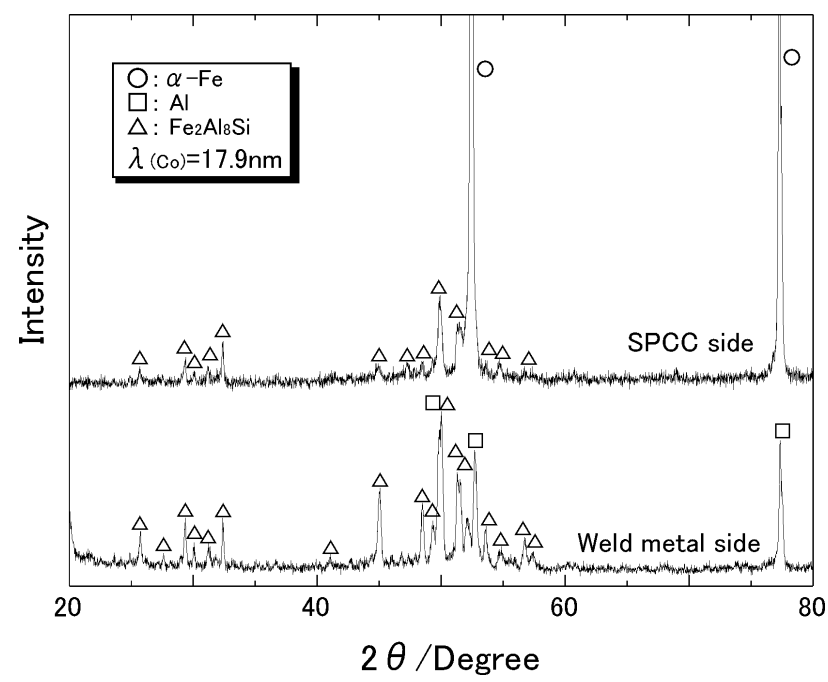

Fig. 10. X-ray diffraction profiles of fractured surface at SPCC/ weld metal interface at welding speed of $0.2 \mathrm{~m} / \mathrm{min}$ and torch aiming position of $0 \mathrm{~mm}$.

$0 \mathrm{~mm}$, respectively. The upper and lower profiles indicate the results on SPCC and weld metal sides, respectively. $\alpha$ Iron and $\mathrm{Al}_{7.4} \mathrm{Fe}_{2} \mathrm{Si}$ were identified at the fractured surface of the SPCC side. On the other hand, $\alpha$-aluminum and $\mathrm{Al}_{74} \mathrm{Fe}_{2} \mathrm{Si}$ were identified at the fractured surface of the weld metal side. Shortly, it is indicated that the welded joint was fractured at the $\mathrm{Al}_{7.4} \mathrm{Fe}_{2} \mathrm{Si}$ intermetallic compound layer. The identified results of the intermetallic compound agree with quantitative one determined by EPMA and EDX.

Figure 11 shows the optimum zone of the welding conditions showing the good weldability together with the fracture mode. The good weldability, which was determined by the tensile test, was obtained in the selected conditions over the welding speed of $0.4 \mathrm{~m} / \mathrm{min}$ and at the range of the aiming position from 0 to $+4 \mathrm{~mm}$. However, insufficient fusion of the joint occurred at the aiming position of $4 \mathrm{~mm}$. In the other conditions, the poor welded joints were obtained due to the thick intermetallic compound layer at the joint interface as shown in Fig. 7. 


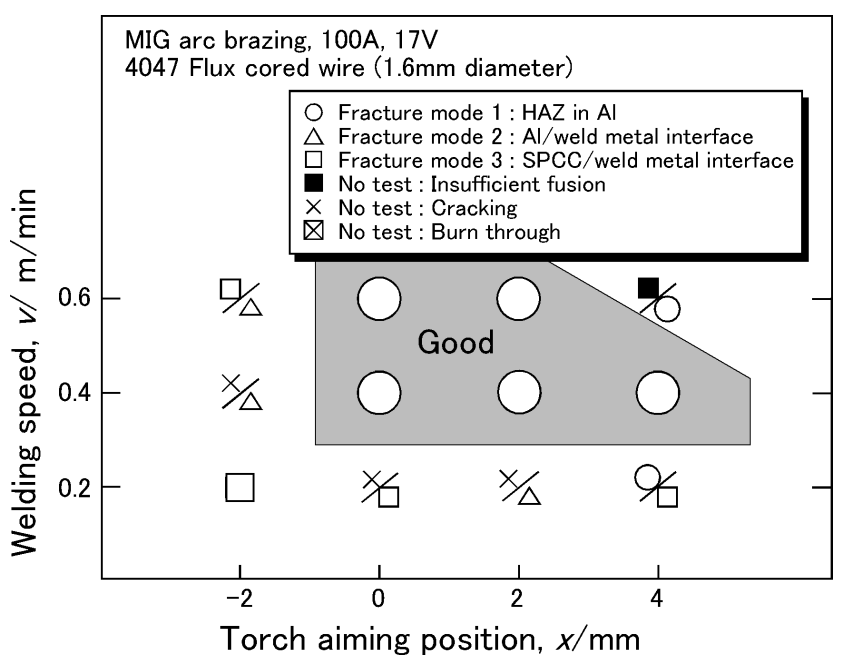

Fig. 11. Optimum zone of welding conditions showing the good weldability together with the fracture mode.

\section{Discussion}

It is important for the obtention of a good dissimilar metal joint to control the growth of the intermetallic compound at the SPCC/weld metal interface. As to the growth mechanism of the intermetallic compound during MIG arc brazing, it is estimated that the difference of the chemical composition and the temperature change by cooling are the driving forces for the growth of the intermetallic compound.

At first the growth of the compound layer induced by the difference of the chemical composition is discussed. When the liquid weld metal whose compositions are shown in Fig. 6 contacted with steel plate, the thin intermetallic compound layer is necessarily generated at the interface because steel and liquid weld metal are not in equilibrium. The mass transfer of alloying elements through the compound layer occurs, which is controlled by the diffusion of the alloying elements since this layer is solid state. The thickness of the growth compound layer, $x$, can be simply calculated assuming the diffusion controlled in the compound and the equation of $x=(4 D t)^{1 / 2}$, where $D$ is the interdiffusion coefficient. It is presumed that $\mathrm{Al}_{74} \mathrm{Fe}_{2} \mathrm{Si}$ forms and grows as a compound layer for the simplification of the mechanism. However, the interdiffusion coefficient in the binary compound of $\mathrm{Al}_{3} \mathrm{Fe}$ is used for the calculation because the interdiffusion coefficient in the Al-Fe-Si ternary compound of $\mathrm{Al}_{7.4} \mathrm{Fe}_{2} \mathrm{Si}$ has not been reported. Akdeniz et $a l$. reported that the presence of $\mathrm{Si}$ in the $\mathrm{Fe}-\mathrm{Al}$ system decreases the diffusion rate of $\mathrm{Al}$ atoms in the Fe matrix leading to reducing the rate of the formation, and hence the brittle intermetallic compound layer formed at the steel/AlSi alloy interface thinned. ${ }^{14)}$ Therefore, it is estimated that the diffusion coefficient of ternary intermetallic compound, $\mathrm{Al}_{7.4} \mathrm{Fe}_{2} \mathrm{Si}$ is smaller than that of binary intermetallic compound, $\mathrm{Al}_{3} \mathrm{Fe}$. The interdiffusion coefficient in $\mathrm{Al}_{3} \mathrm{Fe}$ is reported as a function of temperature, $D\left(\mathrm{~m}^{2} / \mathrm{s}\right)=8.9 \times$ $10^{-8} \exp \left(-117 \times 10^{3} / R T\right),{ }^{15)}$ where $R$ is the gas constant, $8.314 \mathrm{~J} / \mathrm{K} \mathrm{mol}$. When the temperature at the interface is over the decomposition temperature $(973 \mathrm{~K})$ of $\mathrm{Al}_{7.4} \mathrm{Fe}_{2} \mathrm{Si}$, the ternary compound of $\mathrm{Al}_{7.4} \mathrm{Fe}_{2} \mathrm{Si}$ can not generate. The formation and the growth of the compound begin below this temperature. When the temperature falls below the ternary eutectic temperature $\left(T_{\mathrm{e}}=846 \mathrm{~K}\right)$, the mass transfer in the weld metal becomes slow abruptly because of the completion of the solidification. The growth rate of the compound layer by the diffusion decreases abruptly. Therefore, for the calculation as the diffusion temperature, $910 \mathrm{~K}$ is selected, which is the average temperature of 973 and $846 \mathrm{~K}$. The diffusion time at the welding speed of $0.2,0.4,0.6 \mathrm{~m} / \mathrm{min}$ is estimated as 7.5, 2.2 and $0.4 \mathrm{~s}$, respectively, from the results of the thermal cycle. These times approximately correspond to the cooling time from $T_{1}$ to $T_{\mathrm{e}}$. Under these assumptions, the calculated thickness of the compound layers at the welding speed of $0.2,0.4$ and $0.6 \mathrm{~m} / \mathrm{min}$ are $0.7,0.4$ and $0.2 \mu \mathrm{m}$, respectively, and the actual thicknesses formed by diffusion are thinner than the calculated thicknesses. However, the actual thicknesses are $11.1,2.5$ and $0.9 \mu \mathrm{m}$ at these welding conditions, thicker than those of calculated ones. Therefore, it is considered that the diffusion is not the major factor of the growth of the compound.

Another growth mechanism of the compound layer is solidification of the fused weld metal at the interface. The SPCC/weld metal interface is the point of the fastest cooling rate because the supplied heat flows through the SPCC base metal into the copper backing plate on which the SPCC base metal was clamped as shown in Fig. 1. Therefore, the solidification begins at the SPCC/weld metal interface and a primary phase depends on the composition of weld metal. From the experimental result, it is considered that the formed compound layer at the interface is identical with the compound crystallized in the weld metal as the primary phase on the phase diagram and the thickness of the compound layer closely relates to the composition of the welt metal. It is estimated that the growth of the compound layer is mainly controlled by solidification. Thus it is important for decreasing the thickness of the compound layer to control the composition of the weld metal. In particular, the important points are the decrease of the iron content and the control of the composition of the weld metal on the boundary line between the primary region of aluminum and the intermetallic compound, $\mathrm{Al}_{7.4} \mathrm{Fe}_{2} \mathrm{Si}$. Needless to say, the growth factor of the compound layer by solidification is not the composition of the weld metal but the cooling rate. In this study, the effect of the composition of the weld metal on the growth of the compound layer was able to be discussed, because the welding at the constant welding speed kept the cooling rate constant. As the next step, it is required to clarify the effect of the cooling rate of the weld metal on the growth of the compound layer.

\section{Conclusions}

Dissimilar metal joining of aluminum to steel sheet by DC pulsed MIG arc brazing in a lap joint with the flux cored Al-Si filler wire was investigated. The obtained results are summarized as,

(1) Dissimilar metal joining of aluminum to steel sheet without cracking by MIG arc brazing in a lap joint with the flux cored Al-Si filler wire is possible. The optimum zone of the welding conditions such as the welding speed and torch aiming position exists.

(2) The ternary intermetallic compound, $\mathrm{Al}_{7.4} \mathrm{Fe}_{2} \mathrm{Si}$ was 
formed at the interface between steel and weld metal, and in the weld metal. The thickness of the intermetallic compound layer at the interface increased with decreasing the welding speed, and increased as the aiming position moved to aluminum to steel side.

(3) The thickness of the intermetallic compound layer at the steel/weld metal interface can be determined by the composition control of the weld metal, because the growth of the intermetallic compound layer is controlled by solidification. To control the welding conditions as torch aiming position and welding speed can determine the composition of the weld metal.

(4) The transverse tensile strength of the good welded joint, of which the thickness of the intermetallic compound layer was less than $2.5 \mu \mathrm{m}$, fractured at HAZ in aluminum sheet was about $80 \mathrm{MPa}$. This strength equaled to a fraction 0.7 of that of Al base metal due to the softening by the heat affection. When the thickness of the intermetallic compound layer is more than $2.5 \mu \mathrm{m}$, the welded dissimilar joint fractures at the interface between steel and weld metal and has lower strength than the joint fractured at HAZ.

\section{Acknowledgements}

Thanks are offered to Mr. Nagano of Showa Denko for help with the chemical analysis by ICP.

\section{REFERENCES}

1) T. Taka, K. Ogawa and M. Yasuyama: Welding Technique, 41 (1993), 83.

2) H. Oikawa, T. Saito, T. Yoshimura, T. Nagase and T. Kiriyama: $Q . J$. Jpn. Weld. Soc., 14 (1996), 69.

3) H. Ochi, K. Ogawa, Y. Suga, T. Iwamoto and Y. Yamamoto: J. Light Met. Weld. Constr., 32 (1994), 469.

4) M. Kikuchi, H. Takeda and S. Morozumi: J. Jpn. Inst. Light Met., 34 (1984), 165.

5) S. Elliott and E. R. Wallach: Met. Constr., 13 (1981), 167

6) S. Elliott and E. R. Wallach: Met. Constr., 13 (1981), 221.

7) S. Katayama, R. Usui and A. Matsunawa: Proc. 5th Int. Conf. on TREND IN WELDING RESEARCH, ASM International, Materials Park, OH, (1998), 467.

8) E. Schubert, M. Klassen, I. Zerner, C. Walz and G. Sepold: J. Mater. Process. Technol., 115 (2001), 2.

9) E. Schubert, I. Zerner and G. Sepold: Proc. ICALEO '98, Laser Institute of America, Orlando, (1998), Section C, 111.

10) D. R. G. Achar, J. Ruge and S. Sundaresan: Aluminum, 56 (1980), 291.

11) G. Petzow and G. Effenberg: Ternary Alloys: A Comprehensive Compendium of Evaluated Constitutional Data and Phase Diagrams, Vol. 5, VCH, Weinheim, New York, (1988), 415.

12) I. Kawakatsu and T. Osawa: J. Light Met. Weld. Constr., 15 (1977), 160 .

13) M. Roulin, J. W. Luster, G. Karadeniz and A. Mortensen: Supplement to The Welding Research, May (1999), 151s.

14) M. V. Akdeniz, A. O. Mekhrabov and T Yilmaz: Scr. Metall. Mater., 31 (1994), 1723.

15) Metals Reference Book, 6th ed., ed. by C. J. Smithell et al., Butterworth, London, (1983), 13. 